\title{
Multimorbidity and frailty in primary care patients aged 40 years or more in Odisha, India
}

\author{
Subhashisa Swain ${ }^{\mathrm{a}, \mathrm{c}, *}$, Ramesh Chandra Mishra ${ }^{\mathrm{b}}$ \\ a Indian Institute of Public Health-Bhubaneswar, Odisha, India \\ ${ }^{\mathrm{b}}$ Government Dispensary, Salebhata, Bolangir, Odisha, India \\ ${ }^{\mathrm{c}}$ Division of Academic Rheumatology, School of Medicine, University of Nottingham, United Kingdom
}

\section{A R T I C L E I N F O}

\section{Keywords:}

Multimorbidity

Frailty

India

Medication

Hospital visits

\begin{abstract}
A B S T R A C T
Background: Scanty evidence is available on association of multimorbidity with frailty in younger adults. We aimed to investigate the frailty among 40 years or more aged population, it's association with multimorbidity and healthcare utilization.

Methods: This cross-sectional study was done among patients aged $\geq 40$ years attending two randomly selected primary-care centers in Odisha, India using validated tools. Associated factors were identified using multivariate regression.

Results: Out of 364 people contacted, 320 agreed to participate in the study having mean age of 53.39 years. More than $36 \%$ of the study participants were frail. Higher frailty was reported among 60 years or older people (78\%), whereas, nearly $40 \%$ people aged less than 60 years were prefrail. Nearly $50 \%$ of multimorbid people ( $\geq 3$ chronic diseases) were frail. According to multivariate regression, a unit rise in chronic condition count increases the odds of frailty by 3 and 4.5 times in the age group $<60$ and $\geq 60$ years, respectively. After adjusting for other variables, frailty was found to be strongly associated with outpatient visits (Adjusted exp ( $\beta$ coeff): 1.03) whereas, medicine intake count was inversely related.

Conclusion: Frailty and multimorbidity are associated not only among elderly but also in middle aged population. Also, frailty increases the frequency of hospital visits. Thus, attempt should be made to identify frailty in middle age population.
\end{abstract}

\section{Introduction}

Providing quality geriatric health care has become a global challenge, due to rise in multimorbidity and frailty. ${ }^{1}$ Frailty is often used to explain health status of ageing, which increases the vulnerability towards fall, illness and functional decline. ${ }^{2}$ Exact cause of frailty is debatable ${ }^{3}$ however, besides ageing, frailty is linked with a person's life style and as a mediator during transition between healthy life to disability. ${ }^{4}$ Multimorbidity and frailty are increasingly being used in exchange to measure the risk profile of ageing population. ${ }^{1,5}$ When frailty deals with exhaustive and comprehensive assessment of the individual, multimorbidity looks at the chronic diseases. Both are linearly related to ageing, ${ }^{6}$ however, understanding their relation in younger population is essential in the preview of rising non-communicable diseases. It is estimated that, by 2050 worldwide population of older adults may grow to 2 billion, of them $80 \%$ will be from developing countries including India, where ageing population has increased from $6.7 \%$ in the year 1991 to $10 \%$ in 2021 .

Like reported in multimorbidity, frailty carries an increased risk for poor health outcomes. ${ }^{8}$ A study done by Jotheeswaran et al. using data from $10 / 66$ population-based cohort study on frailty and the prediction of dependence and mortality in low and middle income countries reported mortality and dependency to be higher among frailty patients. ${ }^{9}$ Among seven developing countries, the prevalence of frailty and disability was highest in India (55.5\% and $93.3 \%$, respectively) with life expectancy 68.35 years and lowest was seen in China frailty $(13.1 \%)$ and with disability $(69.6 \%)$ with life expectancy of 76 years. ${ }^{10}$ However, so far, most of these assessment are skewed towards elderly, ignoring at-risk middle aged population.

Available frailty assessment tools use physical strength, chronic conditions, cognitive impairment, functional ability and nutrition for screening. ${ }^{11}$ Very few studies have considered multimorbidity to assess frailty. There is a growing consciousness among experts accepting frailty as a diverse syndrome that occurs in elderly individuals.

\footnotetext{
* Corresponding author. Indian Institute of Public Health-Bhubaneswar, Odisha, India.

E-mail address: Subhashisa.Swain@nottingham.ac.uk (S. Swain).
} 
Elucidating its etiology along with multimorbidity in middle age population is critical for identifying high risk subsets. Most of the studies have accessed frailty in elderly population having defined age group of 60 years or more. ${ }^{12}$ Owing to increase in prevalence of chronic diseases, change in life style and early onset of such diseases especially after the age of 40 years, understanding the distribution and risk factors of frailty and its association with multimorbidity and healthcare utilization among young elderly patients would be useful to redesign the health services. To our knowledge, little evidence is available from developing countries on frailty, multimorbidity and health care utilization, especially from primary care settings of India. The aim of the study was to estimate the prevalence and risk factors of frailty level among individuals aged 40 years or more attending primary care and to explore the association between the frailty and healthcare utilization among them.

\section{Methods}

This cross-sectional study was carried out from April to June 2017 in two randomly selected community health center ( $\mathrm{CHC}$ ), out of eight in one district of Odisha, India considering the feasibility (time and logistics).

\subsection{Study participants}

People aged 40 years or more, attending the outpatient department of the selected facilities during the study period were included in the study. Patients having any neurological conditions like stroke/paralysis, severely ill and those who did not give consent to participate were excluded. Considering the prevalence of frailty to be $65 \%$ in India, ${ }^{13}$ with $5 \%$ estimated error, the minimum sample required for the study at $95 \%$ confidence interval was 364 . We decided to take equal number of patients from each facility. Every alternate eligible patient was interviewed by the physician and data was collected in vernacular (local 'Odia') language by the researcher, soon after the consultation with the physician in a calm environment.

\subsection{Study tools}

A semi structure questionnaire was developed and validated before using for the study purpose. The questionnaire collected information on 4 domains; 1. Socio demographic information (Age, Sex, education, occupation, marital status, religion, ethnicity, tobacco use and economic status defined as 'above poverty line' and 'below poverty line' as per the state guideline), ${ }^{14} 2$. Morbidity status of the participants (both communicable and non-communicable) as reported by the subject, 3 . Frailty index by using the frailty assessment tool (Edmonton frailty score tool). ${ }^{15}$

Socio demographic information were recorded as per the participant's response. Data on morbidity was collected as reported and was verified with the prescription/slip and/or medicine covers carried by participants. Grip strength was measured using hand dynamometer for both hands, with arm extended to $90^{\circ}$ and rested on a table in sitting position. Three attempts were made for each hand and the maximum value was used for analysis. Studies have reported grip strength to be better indicator of frailty, ${ }^{16}$ but not in people aged 40 years or more in Indian population. Height and weight was measured for patient to calculate the body mass index (BMI). The extensive list of chronic conditions comprised 21 diseases, which was adopted from our previous study. ${ }^{17}$ Multimorbidity was calculated using simple count methods by adding the number of chronic conditions reported which has been used in previous literature. ${ }^{18}$

Even though various tools are available for estimation of frailty index, we used Edmonton Frail Scale to access the frailty level. The domains of the tool are cognition, general health status, functional independence, social support, medication, nutrition, mood continuance, functional performance. ${ }^{19}$ The tool assigns a score ranging from 0 to 2 for each domain depending on the severity thus the total score ranged from 0 to 17. Health care utilization was recorded in terms of number of outpatient visits in last one month, number of medicines taking daily, and count of hospitalization in last one year. The questionnaire was translated to Odia (local language) and back translated to English version before using in the final study.

\subsection{Data analysis}

The complete questionnaire was checked for completeness and consistency. Age was grouped into two categories, $=<50$ years and more than $>50$ years for analysis purpose considering both multimorbidity and frailty to be higher in ageing population and WHO criteria of older population. Data on morbidity was used to create a new variable on number of morbidities and grouped as multimorbidity $(<3$ conditions) as per the definition. ${ }^{20}$ Totals core for frailty was calculated using the guideline and grouped into five categories namely; not at all (0-5), vulnerable (6-7), mild(8-9), moderate (10-11) and severe (12-17) for graphical presentation and further collapsed into three groups namely robust (0-5), prefrail (6-7) and frail (8-17) for descriptive purposes. For regression model, frailty was used as binary outcome ('No frailty': score 0-7 and 'frailty present': score 8-17). Chisquare test was done to assess the association between explanatory variables and frailty category and ANOVA test was done with Bonferroni correction to test the statistical difference in means reported, at significance level of $\mathrm{p}$ value $<0.05$.

Binary logistic regression model was used to predict the factors responsible for frailty in both the age group adjusting for sex, ethnicity, education, body mass index, number of chronic conditions, grip strength, tobacco habits and economic status. Linear regression model was used to estimate the factors responsible for health care utilization separately for male and female adjusting for age, ethnicity, education, body mass index, number of chronic conditions, frailty score, tobacco habits and socio-economic status.

Prior to the data collection ethical clearance has been obtained from institutional ethics committee. Necessary permission was obtained from all the relevant persons and authorities. Before the interview verbal and written consent was obtained from the participants. The purpose of the study was explained to them before and only voluntarily participation was included in the study. The participants were given chance of any queries or doubts regarding the project and that were answered.

\section{Result}

Out of 364 patients contacted, 342 participated in the study with a non-response rate of $6 \%$. The cited reasons of non-response were lack of time $(n=15)$ and unwillingness $(n=9)$. Mean age of the study participants was 53.39 year [SD 0.58 ] and nearly $44 \%$ were women. Average BMI among men was $21.18 \mathrm{Kg} / \mathrm{M}^{2}$ and $20.55 \mathrm{Kg} / \mathrm{M}^{2}$ in women. On an average, each person reported having 3 morbidities and mean grip strength among men was 10 units higher than women.

Table 1 describes the participants characteristics. More than $36 \%$ of the study participants were frail. Higher frailty was reported among 50 years or older people $(60.5 \%)$, whereas, nearly $40 \%$ people aged less than 50 years were in prefrail category. Statistical significance difference in reporting of frailty was seen across age group and multimorbidity at $\mathrm{p}$ value $<0.05$. Mean number of morbidities differed across thee frailty category with highest among frail patients [2.94; 95\% CI 2.81-3.08] compared to others. The grip strength in both the hand of males and females reduced across the increase in frailty level [Table 2]. Significant difference in mean of age, BMI, morbidity count, grip strength was seen (ANOVA, $\mathrm{p}<0.05$ ). Fig. 1 describes the distribution of frailty across the age group along with prevalence of multimorbidity. Proportion of people being frail increases with age, sharply after the age of 60 years whereas, multimorbidity increases 
Table 1

Sociodemographic distribution across the frailty groups.

\begin{tabular}{|c|c|c|c|c|c|}
\hline Variable & Groups & $\begin{array}{l}\text { Total }(\mathrm{N}=342) \text { Percentage } \\
{[95 \% \mathrm{CI}]}\end{array}$ & $\begin{array}{l}\text { Robust }(\mathrm{N}=98) \text { Percentage } \\
{[95 \% \mathrm{CI}]}\end{array}$ & $\begin{array}{l}\text { Prefrail }(\mathrm{N}=118) \text { Percentage } \\
{[95 \% \mathrm{CI}]}\end{array}$ & $\begin{array}{l}\text { Frail }(\mathrm{N}=126) \text { Percentage } \\
{[95 \% \mathrm{CI}]}\end{array}$ \\
\hline \multirow[t]{2}{*}{ Sex } & Men & $55.62[50.15-61.09]$ & $32.02[25.12-38.92]$ & $33.14[26.18-40.10]$ & $34.83[27.78-41.87]$ \\
\hline & Women & $44.38[38.90-49.84]$ & $27.4[20.06-34.86]$ & $34.50[26.63-42.38]$ & $38.02[29.98-46.07]$ \\
\hline \multirow[t]{2}{*}{ Age group ${ }^{a}$} & $<50$ years & $50.93[45.43-56.44]$ & $46.63[38.91-54.33]$ & $40.49[32.90-48.07]$ & $12.88[7.70-18.06]$ \\
\hline & $>=50$ years & $49.06[43.55-54.56]$ & $12.73[7.48-17.99]$ & $26.75[19.77-33.72]$ & $60.52[52.80-68.20]$ \\
\hline \multirow[t]{2}{*}{ Ethnicity } & $\begin{array}{l}\text { Non-schedule } \\
\text { caste/tribe }\end{array}$ & $56.56[51.10-62.02]$ & $26.51[20.04-32.99]$ & $35.91[28.87-42.49]$ & $37.56[30.46-44.67]$ \\
\hline & $\begin{array}{l}\text { Schedule caste/ } \\
\text { tribe }\end{array}$ & $43.43[37.97-48.89]$ & $34.53[26.56-42.49]$ & $30.93[23.19-38.67]$ & $34.53[26.56-42.48]$ \\
\hline \multirow[t]{3}{*}{ Education } & Illiterate & $63.75[58.45-69.04]$ & $28.43[22.20-34.66]$ & $30.39[24.04-36.74]$ & $41.17[34.38-47.97]$ \\
\hline & Primary & $25.62[20.81-30.43]$ & $32.92[22.65-43.20]$ & $37.80[27.20-48.40]$ & $29.26[19.32-39.21]$ \\
\hline & $\begin{array}{l}\text { High School and } \\
\text { above }\end{array}$ & $10.62[7.23-14.01]$ & $32.35[16.33-48.37]$ & $44.11[27.11-61.12]$ & $23.52[09.00-38.05]$ \\
\hline \multirow[t]{2}{*}{ Tobacco use } & No & $26.25[21.40-31.09]$ & $38.09[27.60-48.58]$ & $26.19[16.69-35.68]$ & $35.71[25.36-46.06]$ \\
\hline & Yes & $73.75[68.90-78.59]$ & $27.11[21.41-32.82]$ & $36.44[30.26-42.61]$ & $36.44[30.26-42.61]$ \\
\hline \multirow[t]{2}{*}{ Socio economic status } & $\begin{array}{l}\text { Above poverty } \\
\text { line }\end{array}$ & $44.37[38.90-49.84]$ & $27.46[20.06-34.86]$ & $33.09[25.30-40.89]$ & $39.43[31.33-47.53]$ \\
\hline & $\begin{array}{l}\text { Below poverty } \\
\text { line }\end{array}$ & $55.63[50.15-61.09]$ & $32.02[25.12-38.92]$ & $34.26[27.25-41.28]$ & $33.70[26.71-40.69]$ \\
\hline Number of chronic & $<$ three & $45.62[40.13-51.11]$ & $39.72[31.73-47.72]$ & $40.41[32.39-48.42]$ & $19.86[13.34-26.38]$ \\
\hline conditions $^{\mathrm{a}}$ & $>=$ three & $54.37[48.88-59.86]$ & $21.83[15.65-28.01]$ & $28.16[21.43-34.88]$ & $50.00[42.52-57.47]$ \\
\hline Total & & $342(100 \%)$ & $30.00[24.95-35.04]$ & $33.75[28.54-38.95]$ & $36.25[30.95-41.54]$ \\
\hline
\end{tabular}

a Significant association with frailty group (Chi square test, $\mathrm{P}$ value $<0.05$ ).

along with the age group. From the age group $40-50$ to 50-60, there is rapid transition from proportion of no-frail and vulnerable to mild and moderate frail category.

We performed two different logistic regression analyses across the age group $(=<50$ years, $>50$ years), as age is one of the strongest risk factors for frailty. In the people aged $=<50$ years, unit rise in number of chronic disease count increases the frailty odds by three times and unit increase in grip strength decreases frailty by 0.9 times after adjusting for other variables. Whereas, among people aged 50 years or more, unit increase in BMI reduces the risk of frailty by 0.8 times and unit increase of chronic disease count increases the odds by 4.4 [95\% CI 1.51-13.05] times after adjusting for other variables [Table 3].

Mean number of healthcare utilization across the frailty group in both sex is depicted in Fig. 2. In both men and women, the mean number of chronic conditions increased with increase in severity of frailty group and highest seen among frail women (mean 3.06) compared to frail men (mean 2.93). Mean number of outpatient visits in past one month in men was seen to increase across the frailty group whereas, among women, no clear trend was seen. Mean number of medicines were found to increase along with frailty severity group in both sex. Among men, statistical significance difference was seen in OPD visits across the frailty group (ANOVA, $\mathrm{P}<0.05$, Bonferroni correction) whereas, in women statistical significance difference was seen in medicine intake across the frailty group (ANOVA, $\mathrm{P}<0.05$, Bonferroni correction). [Figure- 2

Adjusted linear regression model for healthcare utilization is

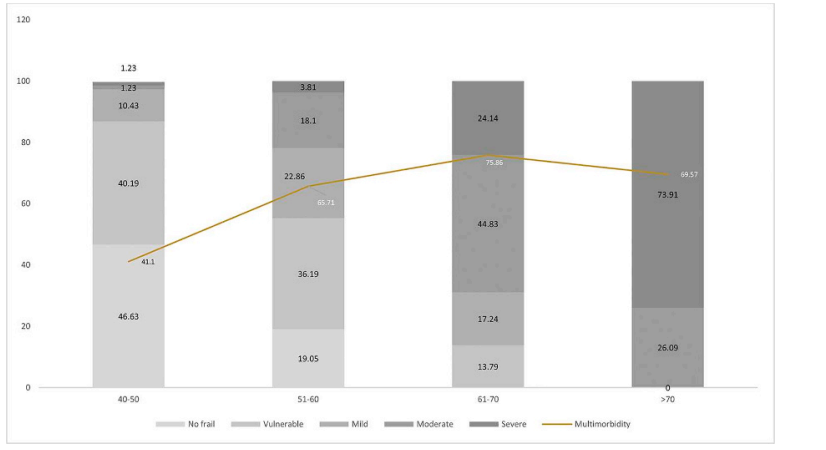

Fig. 1. Distribution of frailty category across the age group in relation to multimorbidity.

Table 3

Logistic regression for factors associated with frailty in different age group.

\begin{tabular}{|c|c|c|}
\hline & $\begin{array}{l}40-50 \text { Years }(\mathrm{n}=173) \\
\text { Adjusted OR }[95 \% \mathrm{CI}]\end{array}$ & $\begin{array}{l}>50 \text { Years }(\mathrm{n}=169) \\
\text { Adjusted OR }[95 \% \mathrm{CI}]\end{array}$ \\
\hline BMI & $1.01[0.91-1.10]$ & $0.81[0.67-0.98]^{*}$ \\
\hline $\begin{array}{l}\text { Hand grip strength } \\
\text { (rt) }\end{array}$ & $0.88[0.81-0.95]^{*}$ & $0.97[0.85-1.10]$ \\
\hline $\begin{array}{l}\text { Hand grip strength } \\
\text { (lt) }\end{array}$ & $1.11[0.97-1.20]$ & $0.98[0.85-1.11]$ \\
\hline $\begin{array}{l}\text { Number of chronic } \\
\text { conditions }\end{array}$ & $3.01[1.68-5.41]^{*}$ & $4.45[1.51-13.05]$ * \\
\hline
\end{tabular}

Table 2

Descriptive values (Mean) across the frailty group.

\begin{tabular}{|c|c|c|c|c|}
\hline Variable & Total $(\mathrm{N}=342)$ Mean $[95 \% \mathrm{CI}]$ & Robust $(\mathrm{N}=98)$ Mean $[95 \% \mathrm{CI}]$ & Vulnerable $(\mathrm{N}=118)$ Mean $[95 \% \mathrm{CI}]$ & Frail $(\mathrm{N}=126)$ Mean [95\%CI] \\
\hline $\operatorname{Age}^{\mathrm{a}}$ & $53.39[52.25-54.52]$ & $46.63[45.48-47.78]$ & $50.13[48.86-51.41]$ & $62.00[60.13-63.87]$ \\
\hline BMI (Female) ${ }^{\mathrm{a}}$ & $20.55[19.81-21.29]$ & $22.52[21.10-23.93]$ & $19.67[18.62-20.71]$ & $19.94[18.68-21.21]$ \\
\hline BMI(Male) ${ }^{\mathrm{a}}$ & $21.18[20.70-21.66]$ & $21.93[21.22-22.76]$ & $21.68[20.93-22.43]$ & $20.01[19.19-20.84]$ \\
\hline Morbidity number $^{\mathrm{a}}$ & $2.59[2.50-2.67]$ & $2.33[2.19-2.47]$ & $2.44[2.31-2.57]$ & $2.94[2.81-3.08]$ \\
\hline Right hand grip strength (Male) ${ }^{\mathrm{a}}$ & $24.85[22.93-26.78]$ & $27.80[24.66-30.95]$ & $29.98[26.97-32.99]$ & $17.27[14.34-20.19]$ \\
\hline Right hand grip strength (Female) ${ }^{\mathrm{a}}$ & $13.91[12.26-15.56]$ & $18.92[16.13-21.71]$ & $15.79[13.58-18.00]$ & $8.59[5.89-11.29]$ \\
\hline Left hand grip strength (Male) ${ }^{\mathrm{a}}$ & $21.98[20.30-23.66]$ & $23.92[21.04-26.81]$ & $25.64[23.33-27.95]$ & $16.70[13.72-19.68]$ \\
\hline Left hand grip strength (Female) ${ }^{\mathrm{a}}$ & $11.23[9.76-12.71]$ & $14.43[11.67-17.19]$ & $12.97[10.89-15.06]$ & $7.35[4.94-9.75]$ \\
\hline
\end{tabular}

${ }^{\mathrm{a}} \mathrm{P}$ value $<0.05$, ANOVA test showing significant differences across the group with bonferoni correction. 


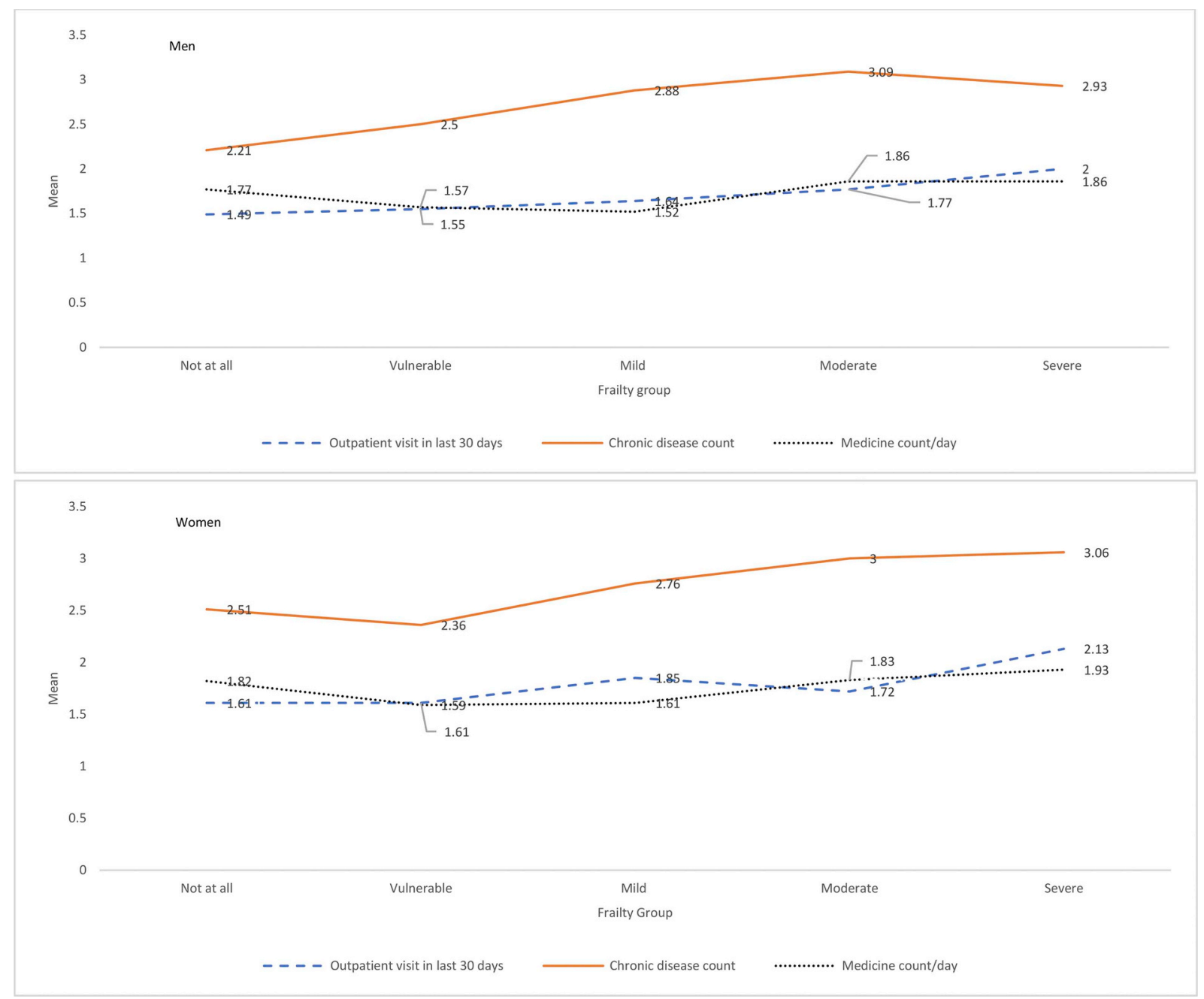

Fig. 2. Mean healthcare utilization and chronic condition count across the frailty group in men (Upper) and women (lower). Among men statistical significance difference was seen in OPD visits across the frailty group (ANOVA, $\mathrm{P}<0.05$, Bonferroni correction). Among women statistical significance difference was seen in medicine intake across the frailty group (ANOVA, $\mathrm{P}<0.05$, Bonferroni correction).

Table 4

Unadjusted and Adjusted model for factors associated with healthcare utilization(OPD visit and medicine taken).

\begin{tabular}{lll}
\hline Variables & OPD visit in last 30 days & Medicines taken per day \\
\cline { 2 - 3 } & $\begin{array}{l}\text { Adjusted B coefficent } \\
{[95 \% \mathrm{CI}]}\end{array}$ & $\begin{array}{l}\text { Adjusted B coefficent } \\
{[95 \% \mathrm{CI}]}\end{array}$ \\
\hline Age & $1.01[0.98-1.02]$ & $1.02[1.01-1.03]^{*}$ \\
BMI & $1.01[0.99-1.03]$ & $1.00[0.98-1.02]$ \\
Number of chronic & $1.09[1.01-1.17]^{*}$ & $1.41[1.27-1.56]^{*}$ \\
$\quad$ conditions & $1.03[1.01-1.06]^{*}$ & $0.92[0.88-0.96]^{*}$ \\
\hline
\end{tabular}

*P values < 0.05; Adjusted for sex, ethnicity, education, socioeconomic status and tobacco use with other variables in the table.

provided in Table 4. Each unit rise in frailty score increases the OPD visits by 1.03 units whereas unit rise in chronic condition count increases it by 1.1 units. However, number medicine use was found to be significantly positively associated with age, chronic condition count and frailty score. After adjusting for sex, age, education, BMI, socioeconomic status, tobacco use, BMI and chronic condition count, each unit rise in frailty score reduces the medicine count by 0.9 units. However, strong linear association was found with chronic conditions count and medicine count after adjusting for other variables [Table 4].

\section{Discussion}

To our knowledge, it is the first study to assess frailty in India aged among 40 years and more. Considering the ageing population, identifying the at-risk population (frail and pre-frail) would help in designing appropriate care model. We attempted to address them in current crosssectional study. Key findings from our study are 1) nearly $13 \%$ of patient aged $=<50$ years were frail and more than $40 \%$ were in pre-frail category, 2) in the age group 40-50, grip strength and chronic condition count and among elderly, BMI and chronic condition count were strongly associated with frailty 3) linear rise in OPD visits was seen with chronic condition count and frailty score whereas, medicine count was significantly associated with age, chronic condition count and frailty score.

In our study nearly, $36 \%$ and $34 \%$ were frail and pre-frail respectively. Previous studies from India reported the prevalence to vary from $30 \%$ to $55 \%$ among people aged 50 years or more ${ }^{21,22}$ less than our findings $(60.5 \%)$. Nearly, $13 \%$ of patients aged $=<50$ years are frail and $40 \%$ are pre-frail. This finding is a clue to extent the research on frailty assessment beyond the elderly population. The reasons of increased proportion in middle age could be due to prevalent chronic conditions. Studies have shown that, multimorbidity and frailty are linked $^{23}$ and multimorbidity in younger age group is common. ${ }^{24}$ In middle age, physiologic process of human body is more active reporting less functional decline, so the possible frailty score is seen to be directly 
linked with count of chronic conditions. As multimorbidity considers the number of chronic conditions in measuring the index, severity score might give better association with frailty. ${ }^{25}$ Another possible reason for increased prevalence could be because of our primary care study settings, where people having diseases and impaired outcomes often visit the health center. However, studies from community based screening have reported the prevalence to be more than $32 \%$ among older population (aged 60 years or more). ${ }^{10,22}$ This could be because of different tools being used for screening of people and better representativeness compared to our facility based population.

We also found strong association with hand grip strength with frailty in people aged $=<50$ years. Similar findings have been reported from developing countries. ${ }^{9,16}$ Hand grip strength, an important marker for assessment of frailty represents physical strength. Thus, exploring the opportunity of using hand grip assessment along with count of chronic conditions in primary care setting could help in identifying 'at-risk' population. Similarly, BMI is one of the significant factors for frailty in elderly population. Recent reports on nutritional status from India explains the burden of undernutrition among elderly population which increases physical and cognitive weakness exposing the person to be frailer. ${ }^{26}$ Literature on BMI and frailty has been nonconclusive. $^{27}$

Linear rise in healthcare utilization with frailty and multimorbidity is consistent with findings from developed countries. ${ }^{28}$ Owing to easier availability and accessibility of primary care services in the country, the increase visits cannot be ignored. We found the significant increase in OPD visits among men only, which could be because of poor health seeking behaviours in women. We did not collect information on type of healthcare use (private or government), however, each visit to facilities are often associated with increased expenditures. Similar findings was reported from hospitalized patients in India ${ }^{22}$ and other developed countries. As each of these studies used different tools to measure frailty, in different population, direct comparison requires more attention. After adjusting for other variables and multimorbidity, frailty was seen to be strongly associated with hospital visits. It is expected that, that frail people, because of their multiple health problems, seek more medical care. ${ }^{29}$ This necessitates further research on types of healthcare utilization and the reasons.

The influential role of count of chronic disease on OPD visit and medicine use is an interesting finding. Frailty is associated with wider healthcare utilization ranging from physiotherapy to alternative medicines and home based care. ${ }^{30}$ We did not collect information on type of services used during their hospital visit, thus, assessing reasons of visit is beyond the scope of our study. Usually, patient with chronic conditions visit the primary care center for follow up which might have inflated the healthcare utilization. People with long-term diseases associated with functional decline often attend specialized care settings. Medicine use and frailty are found to be inversely related. This could be because of increased shift towards alternative therapies in elderly population, especially in India, where alternative and traditional practices are still in use. As our study is based on primary care settings, association of frailty score on medicine use needs careful interpretation.

Being a cross sectional study, we have few limitations. The study sample is from one tribal district of the state, so generalization of the findings should be done with caution. We used self-reported morbidity for listing of chronic diseases, which has its own limitation. However, studies have shown that, self-reported morbidity can be used as a proxy measure for multimorbidity assessment in the absence of electronic records or proper hospital based data. ${ }^{31}$ Another limitation could be the use of Edmonton scale for assessment of frailty, so the findings from our study might require little attention during comparison with other. The healthcare utilization mentioned in the article is on medicine use and hospital visits, as reported by the patients. We have tried to validate the findings with the prescriptions and used medicine covers.

\section{Conclusion}

We found that, frailty is associated with increased count of chronic conditions and healthcare utilization. The higher percentage of frailty among middle age population, demands extension of frailty research to other age group than older population. There is need of modifying the frailty assessment tool, which should provide more weightage to multimorbidity. Even though evidence on multimorbidity and frailty is still debatable, understanding the nexus between these would be helpful in designing appropriate primary care-based intervention.

\section{Conflicts of interest}

The authors declare no conflict of interest.

\section{Funding}

This research did not receive any specific grant from funding agencies in the public, commercial, or not-for-profit sectors.

\section{Acknowledgements}

We thank to all the participants, physicians and nurses who helped us recruiting the participants. We also thank to Department of Health and Family Welfare, Government of Odisha for allowing us for conducting the study.

\section{Appendix A. Supplementary data}

Supplementary data to this article can be found online at https:// doi.org/10.1016/j.cegh.2018.09.003.

\section{References}

1. Marengoni A, Angleman S, Melis R, et al. Aging with multimorbidity: a systematic review of the literature. Ageing Res Rev. 2011;10(4):430-439. https://doi.org/10. 1016/j.arr.2011.03.003.

2. Bock J-O, König H-H, Brenner H, et al. Associations of frailty with health care costs results of the ESTHER cohort study. BMC Health Serv Res. 2016;16(1):128. https:// doi.org/10.1186/s12913-016-1360-3.

3. Dent E, Kowal P, Hoogendijk EO. Frailty measurement in research and clinical practice: a review. Eur J Intern Med. 2016;31:3-10. https://doi.org/10.1016/j.ejim. 2016.03.007.

4. Cesari M, Prince M, Thiyagarajan JA, et al. Frailty: an emerging public health priority. J Am Med Dir Assoc. 2016;17(3):188-192. https://doi.org/10.1016/j.jamda. 2015.12.016.

5. Villacampa-Fernández P, Navarro-Pardo E, Tarín JJ, Cano A. Frailty and multimorbidity: two related yet different concepts. Maturitas. 2017;95:31-35. https://doi org/10.1016/j.maturitas.2016.10.008.

6. Abizanda P, Rodríguez-Mañas L. Function but not multimorbidity at the cornerstone of geriatric medicine. J Am Geriatr Soc. 2017;65(10):2333-2334. https://doi.org/10. 1111/jgs.15021.

7. Dsouza SA, Rajashekar B, Dsouza HS, Kumar KB. Falls in Indian older adults: a barrier to active ageing. Asian J Gerontol Geriatr. 2014;9(1):33-40.

8. Arokiasamy $\mathrm{P}$, Uttamacharya $\mathrm{U}$, Jain $\mathrm{K}$, et al. The impact of multimorbidity on adult physical and mental health in low- and middle-income countries: what does the study on global ageing and adult health (SAGE) reveal? BMC Med. 2015;13:178. https:// doi.org/10.1186/s12916-015-0402-8.

9. AT J, Bryce R, Prina M, et al. Frailty and the prediction of dependence and mortality in low- and middle-income countries: a 10/66 population-based cohort study. BMC Med. 2015;13:138. https://doi.org/10.1186/s12916-015-0378-4.

10. Biritwum RB, Minicuci N, Yawson AE, et al. Prevalence of and factors associated with frailty and disability in older adults from China, Ghana, India, Mexico, Russia and South Africa. Maturitas. 2016;91:8-18. https://doi.org/10.1016/j.maturitas.2016. 05.012 .

11. Buta BJ, Walston JD, Godino JG, et al. Frailty assessment instruments: systematic characterization of the uses and contexts of highly-cited instruments. Ageing Res Rev 2016;26:53-61. https://doi.org/10.1016/j.arr.2015.12.003.

12. Barnett K, Mercer SW, Norbury M, Watt G, Wyke S, Guthrie B. Epidemiology of multimorbidity and implications for health care, research, and medical education: a cross-sectional study. Lancet. 2012;380(9836):37-43. https://doi.org/10.1016/ S0140-6736(12)60240-2.

13. Agrawal S, Llyod-Sherlock P, Minicuci N. Frailty and its Association with Geriatric 
Depression in India: Evidence from the WHOSAGE. 2016; 2016https://www.ifa-fiv.org/ wp-content/uploads/2013/03/264.pdf.

14. Government of Odisha. District Wise Soioeconomic Indicator of Odisha. 2001; 2001http://odisha.gov.in/census/cenmain.htm, Accessed date: 16 August 2016.

15. Perna S, Francis MD, Bologna C, et al. Performance of Edmonton Frail Scale on frailty assessment: its association with multi-dimensional geriatric conditions assessed with specific screening tools. BMC Geriatr. 2017;17:2. https://doi.org/10.1186/s12877016-0382-3.

16. Dudzińska-Griszek J, Szuster K, Szewieczek J. Grip strength as a frailty diagnostic component in geriatric inpatients. Clin Interv Aging. 2017;12:1151-1157. https://doi. org/10.2147/CIA.S140192.

17. Pati S, Hussain MA, Swain S, et al. Development and validation of a questionnaire to assess multimorbidity in primary care: an indian experience. BioMed Res Int. 2016;2016. https://doi.org/10.1155/2016/6582487.

18. Diederichs C, Berger K, Bartels DB. The measurement of multiple chronic diseases-a systematic review on existing multimorbidity indices. $J$ Gerontol A Biol Sci Med Sci. 2011;66(3):301-311. https://doi.org/10.1093/gerona/glq208.

19. Rolfson DB, Majumdar SR, Tsuyuki RT, Tahir A, Rockwood K. Validity and reliability of the Edmonton frail scale. Age Ageing. 2006;35(5):526-529. https://doi.org/10. 1093/ageing/afl041.

20. Harrison C, Britt H, Miller G, Henderson J. Examining different measures of multimorbidity, using a large prospective cross-sectional study in Australian general practice. BMJ Open. 2014;4(7):e004694https://doi.org/10.1136/bmjopen-2013004694.

21. Nguyen TN, Cumming RG, Hilmer SN. A review of frailty in developing countries. $J$ Nutr Health Aging. 2015;19(9):941-946. https://doi.org/10.1007/s12603-0150503-2.

22. Khandelwal D, Goel A, Kumar U, Gulati V, Narang R, Dey AB. Frailty is associated with longer hospital stay and increased mortality in hospitalized older patients. $J$ Nutr Health Aging. 2012;16(8):732-735. https://doi.org/10.1007/s12603-012-
0369-5.

23. Boeckxstaens P, Vaes B, Legrand D, Dalleur O, Sutter AD, Degryse J-M. The relationship of multimorbidity with disability and frailty in the oldest patients: a crosssectional analysis of three measures of multimorbidity in the BELFRAIL cohort. Eur $J$ Gen Pract. 2015;21(1):39-44. https://doi.org/10.3109/13814788.2014.914167.

24. Pati S, Swain S, Hussain MA, Kadam S, Salisbury C. Prevalence, correlates, and outcomes of multimorbidity among patients attending primary care in Odisha, India. Ann Fam Med. 2015;13(5):446-450. https://doi.org/10.1370/afm.1843.

25. Boeckxstaens P, Sutter AD, Vaes B, Degryse J-M. Should we keep on measuring multimorbidity? J Clin Epidemiol. 2016;71:113-114. https://doi.org/10.1016/j. jclinepi.2015.05.015.

26. Swain S, Chowdhury S. Trends of nutritional status among rural adults in six states of India: findings from national survey data. Clin Epidemiol Glob Health. 2018;0(0) https://doi.org/10.1016/j.cegh.2017.12.009.

27. Fried LP, Tangen CM, Walston J, et al. Frailty in older AdultsEvidence for a phenotype. J Gerontol Ser A. 2001;56(3):M146-M157. https://doi.org/10.1093/gerona/ 56.3.M146.

28. McNallan SM, Singh M, Chamberlain AM, et al. Frailty and healthcare utilization among patients with heart failure in the community. JACC Heart Fail. 2013;1(2):135-141. https://doi.org/10.1016/j.jchf.2013.01.002.

29. Bowling CB, Plantinga L, Phillips LS, et al. Association of multimorbidity with mortality and healthcare utilization in chronic kidney disease. $J$ Am Geriatr Soc. 2017;65(4):704-711. https://doi.org/10.1111/jgs.14662.

30. Ilinca S, Calciolari S. The patterns of health care utilization by elderly Europeans: frailty and its implications for health systems. Health Serv Res. 2015;50(1):305-320. https://doi.org/10.1111/1475-6773.12211.

31. Roberts RO, Bergstralh EJ, Schmidt L, Jacobsen SJ. Comparison of self-reported and medical record health care utilization measures. J Clin Epidemiol. 1996;49(9):989-995. https://doi.org/10.1016/0895-4356(96)00143-6. 